\title{
¿Mesianismo salesiano en Patagonia septentrional? Último cuarto del siglo XIX, pueblo General Roca
}

\author{
María Alejandra EsTRADA \\ CONICET - Departamento de Arqueología, Universidad Nacional de La Plata. \\ estradamariaa@yahoo.com.ar
}

Recibido: 8 de octubre de 2009

Aceptado: 15 de octubre de 2010

\begin{abstract}
RESUMEN
La congregación salesiana llegó a Argentina en el año 1875; su misión principal consistió en evangelizar, educar y «civilizar» a los aborígenes radicados en Patagonia, pero no logró ingresar en ella hasta cuatro años después. Una vez asentada allí, sus integrantes comenzaron a practicar misiones itinerantes, a fundar distinta clase de instituciones y en 1883 establecieron un Vicariato Apostólico para Patagonia Septentrional y Central y una Prefectura Apostólica para Patagonia Meridional. La documentación analizada demuestra que los salesianos asumieron su labor como redentora e incluso mesiánica, caracteres que los indígenas nunca les atribuyeron. Este trabajo se ocupa del desarrollo de esta situación en Patagonia septentrional durante el último cuarto del siglo XIX, particularmente en la población de General Roca.
\end{abstract}

Palabras claves: Patagonia, Misiones salesianas, redención, aborígenes.

\section{Salesian Messianism in Northern Patagonia? Last Quarter of $19^{\text {th }}$ Century, General Roca Town}

\begin{abstract}
The Salesian order arrived Argentina in 1875 and four years later settled in Patagonia; its main mission was to evangelize, educate and «civilize» the natives who lived there. Once stablished, the Salesians began practicing itinerant missions to form different kinds of institutions and in 1883 created the Apostolic Vicariate of Northern and Central Patagonia and the Apostolic Prefecture for the Southern Patagonia. The documents reviewed show that the Salesians took their work as redemptive and even messianic; however, the Indians never assigned them those features. This paper addresses the development of this situation in Northern Patagonia during the last quarter of the nineteenth century, particularly in the town of General Roca.
\end{abstract}

Key words: Patagonia, Salesian missions, redemption, natives.

SUMARIO: 1. Introducción: La congregación salesiana en Argentina y Patagonia (primeros años). 2. Los comienzos de General Roca. 3. Población aborigen de General Roca. 4. Misiones itinerantes en Patagonia septentrional: General Roca, 1880-1889. 5. Centro misional de General Roca: 1889-1899. 6. Indígenas y blancos bajo el caleidoscopio salesiano. 7. Discusión. 8. Conclusiones. 9. Referencias bibliográficas.

\section{Introducción: La congregación salesiana en Argentina y Patagonia (primeros años)}

El marco temporal que comprende este trabajo abarca el último cuarto del siglo XIX, desde la llegada de los salesianos a Argentina hasta la destrucción de General Roca en el año 1899. Esta localidad fue seleccionada a partir de la gran cantidad de aborígenes que se instalaron en sus inmediaciones, de las misiones ambulantes que se practicaron en ella y del establecimiento de una sede fija en $1889^{1}$.

\footnotetext{
${ }^{1}$ Los términos «aborigen», «indígena» $\mathrm{y}$ «natural» se emplean aquí como sinónimos.
} 
La congregación salesiana fue creada en el año 1859 en Turín, Italia. Su fundador, Juan Bosco (1815-1888), organizó una sociedad civil bajo la advocación de San Francisco de Sales, constituida por sacerdotes y laicos (Archivo Histórico Salesiano de Patagonia Norte s/f). Desde su apertura la institución centró su interés en problemáticas vinculadas con la evangelización, la asistencia social y la educación de niños y jóvenes, y también en el porvenir espiritual y social de connacionales migrados a otros países. En el año 1874 el cónsul argentino de Savona (Italia), Juan Gazzolo, tuvo un encuentro con Juan Bosco y tomó conocimiento de su obra; le propuso entonces al arzobispo de Buenos Aires, Federico Aneyros, que incorporara a estas tierras la labor de la congregación y fue así como el superior salesiano recibió la invitación de participar de las tareas cristianas que Aneyros desarrollaba en Argentina. En ese momento el obispado de Buenos Aires incluía bajo su jurisdicción todo el territorio patagónico, pero sus actividades dentro del mismo llegaban hasta Mercedes de Patagones -población estable más austral-, porque el espacio restante se hallaba bajo dominio indígena ${ }^{2}$. Juan Bosco aceptó la propuesta porque le permitiría cumplir con el precepto de atender el bienestar de inmigrantes italianos, pero hubo una razón más fuerte que lo conmovió. Consiguió elucidar dos «sueños» experimentados en 1854 y 1872, que había interpretado como «visiones» o «avisos del cielo» (Paesa 1964b). El primero tuvo lugar cuando al entrar en el cuarto del convaleciente jovencito Juan Cagliero, alumno del instituto que dirigía, «visualizó» que el niño llegaría a consagrarse obispo y «contempló alrededor del lecho una multitud de extrañas figuras de salvajes, que fijaban sus miradas en el rostro del enfermo pidiéndole socorro» (Paesa 1964b: 17). El segundo, más extenso y minucioso, se describe a continuación, a partir de la narración que el misionero Alejandro Stefenelli hizo en su biografía, habiendo oído el relato de boca del propio Juan Bosco. Este «sueño» permitirá lograr un mayor acercamiento a las ideas y proyecciones que el superior abrazó en torno a Patagonia:

«Juan Bosco se descubría en una región lejana, 'una inmensa llanura desértica' delimitada por montañas, recorrida por 'turbas de hombres salvajes', altos, 'de aspecto feroz', rostro bronceado, cabellos hirsutos y largos, cubiertos con pieles de animales y armados de lanzas. Esparcidos aquí, agrupados allá, algunos cazaban, otros gritaban y blandían sus armas, luchaban entre ellos o arremetían contra soldados europeos con los que sembraban el terreno de cadáveres. En un extremo de la meseta aparecían misioneros de diversas familias religiosas que iban a predicar entre esos 'temibles bárbaros', pero eran embestidos con un 'furor diabólico', torturados, asesinados y descuartizados 'con saña feroz'. Se presentaba luego una segunda comitiva integrada por jóvenes salesianos y '...aquella turba de bárbaros miserables comparecía ante ellos, con sus armas bajas, alegres, cesando su natural ferocidad para recibirlos con signos de sincera cortesía...'. Los misioneros penetraban en esa ' ...horda domesticada de hijos del desierto y los instruían. Aquellos bárbaros escuchaban de buena gana y aprendían rápidamente las oraciones y cánticos cristianos, aceptaban las reprensiones que les hacían y ponían en práctica sus consejos...' Los 'salvajes' les abrían paso y se arrodillaban ante ellos» (Archivo Histórico Salesiano de Patagonia Norte s/f: 28).

\footnotetext{
${ }^{2}$ Actual ciudad de Viedma, ubicada sobre la margen sur del río Negro, próxima a su desembocadura en el océano Atlántico.
} 
Excepto por la interpretación del obispado de Cagliero, Juan Bosco no había conseguido determinar a qué aludían las restantes imágenes de la primera «visión» ni de la segunda. Puesto que creía que una de las funciones esenciales de la congregación consistía en misionar entre individuos de tierras lejanas, y que en distintas ocasiones había enviado salesianos a Egipto, China, Australia y Mangalore, concibió la idea de que los paisajes y personajes de sus «visiones» podían pertenecer a alguno de estos sitios; sin embargo, ni el ambiente ni los habitantes coincidían (Paesa 1964b: 18-19). Cuando recibió el ofrecimiento de misionar en Argentina comenzó a buscar información acerca del país y, en las descripciones e ilustraciones que observó, asoció a los indígenas de sus «sueños» con los «salvajes» de Patagonia y Tierra del Fuego (Paesa 1964b: 17). En su memoria biográfica expresó: «...desde entonces vi con toda claridad la región hacia la que debía dirigir todos mis esfuerzos» (Paesa 1964b: 19-20). En ese momento asumió que la misión que se le había adjudicado a través de los «avisos del cielo» consistía en evangelizar, educar y «civilizar» a los residentes naturales del sur argentino (Yorio 2003).

El primer contingente de salesianos arribó a la República en el mes de diciembre de 1875 y se dividió en dos grupos, uno se instaló en el centro de Buenos Aires, en la capilla Mater Misericordiae, y el otro en San Nicolás de los Arroyos; estos centros y la parroquia de la Boca del Riachuelo, en la que la institución empezó a trabajar al año siguiente, se ocuparon fundamentalmente de inmigrantes italianos.

Juan Bosco pedía constantemente a sus discípulos que se radicaran en Patagonia y fundaran establecimientos religiosos y educativos, pero éstos no se atrevían a aventurarse solos en ese espacio, porque lo desconocían completamente y habían oído que algunas agrupaciones indígenas guardaban una fuerte hostilidad hacia el blanco. Por esos años la posibilidad de asentarse en el sur argentino se reducía a dos opciones:

1. Carmen de Patagones, población ubicada sobre la margen norte del río Negro, próxima a su desembocadura en el océano Atlántico, que presentaba la parroquia más austral del país. Esta alternativa quedó vedada al finalizar el año 1876, porque Aneyros concedió la regencia del templo y la evangelización de todo el territorio patagónico a la orden lazarista. Sin embargo, esta entidad no logró reunir los recursos económicos y humanos necesarios para llevar adelante la empresa y en enero de 1878 presentó su renuncia.

2. La segunda alternativa consistía en aguardar a que el Estado tomara posesión efectiva de Patagonia, posibilidad que comenzaría a desarrollarse en abril de 1879, ya que el ejército, por orden y en representación del Estado, emprendió una expedición de avance de la frontera sur de la República hasta los ríos Negro y Neuquén, con el objeto de consolidar la soberanía nacional sobre el espacio ubicado a retaguardia de esas vías fluviales. Julio Roca, director de la operación, enterado de los deseos de la congregación de trabajar en el sur, invitó a los salesianos a marchar junto a su columna. La institución aceptó la propuesta y durante el trayecto se ocupó del adoctrinamiento de los aborígenes interceptados, de los indios amigos que integraban la tropa, de soldados, de oficiales y de las poblaciones indígenas y blancas localizadas en las inmediaciones de las rutas de avance ${ }^{3}$. Finalizada la expedición en el mes de junio los

${ }^{3}$ Se denominaba indios amigos a los aborígenes que se relacionaban con el gobierno a través de tratados de 
misioneros regresaron a Buenos Aires.

En agosto de 1879 Aneyros ofreció a Juan Bosco la parroquia de Carmen de Patagones y la evangelización de los habitantes patagónicos, oferta que el rector aceptó de inmediato (Bruno 1992: 68). De este modo, ambas opciones en principio inalcanzables se abrieron a la entidad de manera casi simultánea. En enero de 1880 la congregación se estableció en la localidad mencionada y enseguida comenzó a evangelizar a los naturales dispersos a lo largo de los ríos Negro y Neuquén, muchos de ellos emplazados junto a los asentamientos cívico-militares instalados tras la expedición del año precedente. En la medida que el Estado extendía su soberanía, estas andanzas se incrementaron espacio-temporalmente y permitieron a los misioneros el acceso a distintos rincones de Patagonia, y también tomar conciencia de las dimensiones de esa vasta superficie. La necesidad de organizar la administración espiritual y educativa del área promovió la creación en el año 1883 del Vicariato Apostólico de Patagonia Septentrional y Central, con jurisdicción en las actuales provincias de Neuquén, Río Negro y Chubut, y la Prefectura Apostólica de Patagonia Meridional, de competencia en Santa Cruz, Tierra del Fuego e islas del Atlántico sur. Ambas instituciones fueron reconocidas por el Vaticano pero no por el arzobispado de Buenos Aires (Nicoletti 2006: 3). La primera estuvo a cargo de Juan Cagliero, y en ella se optó por la realización de misiones móviles, trasladándose los salesianos hasta los indígenas y procurando cubrir la mayor cantidad de agrupaciones posibles en cada desplazamiento; este proceder permitió evangelizar a un gran número de aborígenes, pero tuvo el inconveniente de constituir un adoctrinamiento esporádico e inconstante. Además, los circuitos debían cubrir espacios muy amplios, y según manifestaron algunos sacerdotes los recursos humanos, materiales y económicos no permitían desarrollar plenamente esta modalidad. En la Prefectura, administrada por José Fagnano, se practicaron misiones ambulantes y también se organizaron algunas reducciones en Tierra del Fuego, siendo en este caso los naturales quienes se movilizaron hacia los misioneros, radicándose junto a ellos por periodos prolongados o arrimándose con frecuencia pero sin llegar a establecerse. A pesar de que bajo estas condiciones la evangelización fue más constante, la labor salesiana resultó insuficiente debido a que el número de reducciones fue escaso con relación al terreno y la cantidad de habitantes que debía cubrir (Nicoletti 2005: 10). Algunos salesianos consideraron ineficaz el procedimiento implementado en el Vicariato, sustentando la conveniencia de abrir reducciones en toda Patagonia y complementarlas con misiones ambulantes, en tanto otros apoyaron la realización de circuitos móviles y restaron efectividad a las reducciones. A fin de hallar un punto medio y cumplir con la voluntad de Juan Bosco se inauguraron varios centros misionales en diferentes puntos del sur argentino, que permitieron a las poblaciones indígenas radicarse de manera esporádica o prolongada junto a los mismos y también facilitaron el traslado de oradores hasta las agrupaciones que permanecieron alejadas

paz, en los cuales éste solía adjudicar títulos militares a las personalidades principales de las tribus y se comprometía a proveerlas de sueldos, ganado, artículos de consumo (alimentos, vestimenta, «vicios» -alcohol, tabaco y yerba, entre otros-) y mercancías diversas, en tanto los indígenas garantizaban no atacar las poblaciones blancas, defenderlas en invasiones ejecutadas por otros grupos y prestar a las autoridades civiles y militares distinta clase de servicios: informativos, combativos, secundar tropas de carros por la campaña, etc. (Ratto 1999). 
de los núcleos huincas ${ }^{4}$. Estos centros fueron principalmente religiosos y educativos, fundándose iglesias, escuelas de enseñanza elemental, de artes y oficios, de agricultura, asilos, hospitales, oratorios y observatorios meteorológicos.

En el año 1884 cobró realidad la primera «visión» de Juan Bosco al consagrarse obispo en Mercedes de Patagones el salesiano Juan Cagliero, instituyéndose como el primer prelado de Patagonia. El vínculo entre esta «visión» y las restantes quedó en evidencia frente a la dedicación con que este salesiano misionó en las tierras del Vicariato, incluida la localidad de General Roca.

\section{Los comienzos de General Roca}

El 1 de septiembre de 1879, casi tres meses después de finalizada la expedición de Julio Roca, el teniente coronel Lorenzo Vintter fundó el fuerte General Roca en el paraje indígena Fisque Menuco, con el objeto de resguardar de incursiones aborígenes un amplio sector de la nueva frontera (Estrada 2008). Este punto se hallaba sobre la margen norte del río Negro, en la zona posteriormente denominada «Alto Valle», dentro de la superficie que en 1884 constituiría el territorio nacional de Río Negro ${ }^{5}$. Se trataba de un lugar estratégico, de condiciones ampliamente favorables, que contaba con agua, suelo fértil, pastos fuertes, leña, numerosos caminos, accesibilidad por tierra y por agua, estaba posicionado entre la cordillera y el mar e integraba el conocido «camino de los chilenos» ${ }^{6}$ (Rojas Lagarde 2004). En el año 1881 el fuerte fue declarado pueblo, porque no sólo era asiento de destacamentos militares sino también de numerosos civiles y varios grupos indígenas que se habían establecido dentro del núcleo urbano y en sus proximidades. Esta concentración aborigen constituyó una fuerte atracción para los salesianos, quienes entre 1880 y 1889 llevaron varias misiones itinerantes al sitio, fundando en esta última fecha un centro misional fijo, después de advertir que las asistencias esporádicas resultaban insuficientes para alcanzar sus objetivos.

\section{Población aborigen de General Roca}

En General Roca se asentaron numerosos caciques con sus tribus, entre ellos: Namuncurá, Manquel, Reuque Curá, Sayhueque, Llanquetruz, Curruhuinca, Ñancucheo, Cañel, Mariano y Catriel (Estrada 2008). Algunos se establecieron en forma provisional en tanto a aguardaban que el Estado les concediera una heredad, otros emplearon el sitio como lugar de paso y un tercer grupo optó por radicarse de manera indefinida.

\footnotetext{
${ }^{4}$ Vocablo empleado por los naturales para referirse al blanco o los objetos propios de su cultura (Irurtia 2002)

${ }^{5}$ En el año 1884 Patagonia fue dividida en los territorios nacionales de Río Negro, Neuquén, Chubut, Santa Cruz y Tierra del Fuego.

${ }^{6}$ Red de rutas que atravesaban la región pampeana y norpatagónica, a través de la cual los aborígenes conducían ganado robado hacia Chile.
} 
La pobreza en la que quedaron sumidos los naturales después de ser expropiados de sus tierras en 1879 los instó a radicarse cerca de núcleos huincas para recibir las raciones de alimentos que el Estado les proporcionaba. En alusión al desarrollo de esta situación dentro del pueblo, un informe del ejército señala en 1885: «Muchos quedan todavía aquí establecidos con chacras en que cultivan la agricultura, y pocos, viejos o inválidos en su totalidad, reciben todavía raciones del gobierno» (Ministerio de Guerra y Marina 1886: 433). El documento pretende denotar que sólo se racionaba a personas con capacidades disminuidas porque los demás obtenían recursos de sus propias parcelas. Sin embargo, este comentario es rebatido por otros expedientes que aseguran que las chacras mencionadas no eran propiedad de los indígenas sino que se trataba de espacios tomados, ya que si bien antes de su rendición el gobierno se había comprometido a entregarles terrenos, muy pocos los habían recibido. La dificultad de acceder legalmente a ellos exhortaba a muchos a trabajar en propiedades del blanco, donde en general también se les permitía residir. Declarar que el racionamiento se entregaba a minusválidos y ancianos también intentaba exhibir una faceta estatal caritativa, actitud poco creíble para una institución que siempre procuró el avasallamiento aborigen. La alteración de la información fue un ardid empleado con frecuencia por diferentes entidades para desdibujar sus atropellos sobre los naturales.

El segundo grupo de indígenas (aquellos que utilizaron el sitio como lugar de paso) estuvo integrado por aborígenes sometidos que pasaron por el paraje cuando se dirigían a otros sectores del territorio y por prisioneros capturados en patrullajes militares.

Los naturales que se asentaron por tiempo indefinido se alojaron dentro del radio urbano, mantuvieron vínculos estrechos con el blanco, se adaptaron a su forma de vida y en algunos casos formaron familias mestizas: «Los indios y las chinas se confunden ya en sus trajes y hábitos con nuestros campesinos y el idioma mismo se pierde sensiblemente» (Ministerio de Guerra y Marina 1886: 433).

La presencia de indígenas en el lugar fue registrada en numerosos manuscritos, elaborados por funcionarios del Estado, salesianos, militares, científicos, viajeros y particulares. En 1882 el misionero José Fagnano describió al asentamiento como un destacamento de soldados donde había muchos «indios» (Paesa 1964a). Un año después otro salesiano, Domingo Milanesio, comunicaba a Juan Bosco que en el mes de abril había permanecido 11 días en General Roca, impartiendo doctrina y bautismos a más de un centenar de «jóvenes indios del cacique Manquel», asentado en el pueblo junto a su gente desde el año anterior ${ }^{7}$ (Paesa 1964a). En otra carta le manifestaba que unos meses más tarde había vuelto a misionar en esa tribu y también en la del cacique Reuque Curá y que el día que se marchaba habían llegado al sitio «otros 150 indios pertenecientes a diversas tribus dispersadas por el territorio» (Paesa 1964a: 22). Hilarión Furque, cronista del diario La Prensa, visitó el lugar en 1882 y expuso que la tribu de Reuque Curá se componía de lanzas, chusma y unos cincuenta miembros de la «familia real» del cacique, también expresó que residían allí desde 1882 y que junto con la gente de Manquel reunían unas 500 personas (Zeballos 1885: 104). Un informe militar escrito el día 2 de febrero de 1884 demuestra que para esa fecha ambos caciques aún permanecían en el pueblo, encontrándose Manquel con 616 personas, Reuque

${ }^{7}$ El sacerdote José María Beauvoir también participó en esta misión 
Curá con 271 y 73 prisioneros de diferentes agrupaciones (Ministerio de Guerra y Marina 1884).

Berta Rival, preceptora y maestra de la escuela mixta del asentamiento, declaró haber visto en 1884 unos quinientos naturales de la tribu de Manuel Namuncurá 8 , agrupación que se estableció un tiempo en proximidades del núcleo poblacional. Un documento del ejército releva que el 25 de abril de este mismo año se presentaron en el sitio «20 indios con 10 familias» y el 29 de mayo se sometieron voluntariamente «71 indios, 51 mujeres y 44 menores» (Ministerio de Guerra y Marina 1885).

El primer censo territorial de Río Negro realizado en el año 1886 determinó que el pueblo tenía 817 habitantes, de los cuales el 25\% era aborigen (Gorla 1973). Estos números señalan que para ese momento las tribus de Manquel, Reuque Curá y Namuncurá no se hallaban en el sitio, o al menos no en su totalidad, porque, con la presencia incluso de la más reducida, la proporción apuntada habría sido mayor. Pese a la retirada de esas agrupaciones, los expedientes demuestran que algunos integrantes se quedaron en el lugar. El análisis de diversos manuscritos permitió inferir que la densidad indígena previa al empadronamiento fue superior y que el porcentaje de naturales disminuyó en el transcurso del tiempo, producto de movilizaciones voluntarias y por adjudicación de tierras en otros parajes. El Ministerio de Guerra y Marina (1886: 433) notifica que en 1885 la Comandancia militar de General Roca «dio de baja» a muchos aborígenes que solicitaron autorización para retirarse a las poblaciones rurales de la costa de Río Negro y de la provincia de Buenos Aires en busca de trabajo. Un informe de 1889 confirma la merma indígena al expresar que en ese momento su proporción no superaba el 10\% (Furque 1889).

El censo nacional de 1895 asigna al sector urbano del pueblo 849 habitantes y al rural 542, de cuyo total los naturales no constituían el 5\%. Tres años después la población urbana superaba el millar (Bello 1898: 17-18).

Más allá de que alguno de los valores demográficos citados pueda ser inexacto y de que la concentración aborigen osciló y decreció a través del tiempo, la presencia de indígenas en el sitio fue continua.

\section{Misiones itinerantes en Patagonia septentrional: General Roca, 1880-1889}

Entre 1880 y 1889 numerosos salesianos misionaron en General Roca, destacándose entre ellos Domingo Milanesio, Juan Cagliero, Santiago Costamagna, José Fagnano, José Beauvoir, Emilio Rizzo, Andrés Pestarino y Alejandro Stefenelli. La distinción de estos individuos se centró en las reiteradas ocasiones en que visitaron el lugar y las actividades que desarrollaron. Emilio Rizzo fue el primer salesiano que misionó en General Roca; lo hizo en el año 1880, en compañía de monseñor Mariano Espinosa, representante del arzobispado de Buenos Aires. Andrés Pestarino y Alejandro Stefenelli fueron los últimos integrantes de la congregación que se arrimaron al pueblo

\footnotetext{
${ }^{8}$ El cálculo deviene exagerado ya que las crónicas indican que en el mes de abril Namuncurá se presentó en el sitio acompañado por 213 individuos a los que luego se incorporaron otros 118, y ellos constituían la totalidad de la tribu.
} 
para adoctrinar a sus habitantes, suceso que tuvo lugar en el año 1887. Si bien el segundo misionero visitó el sitio en esta única oportunidad, su actividad cobró mayor trascendencia que la del resto porque fue el único que se atrevió a abrir y dirigir una delegación, inaugurada en el año 1889 , y de la cual estuvo al frente hasta su retiro en $1913^{9}$ (Estrada 2006).

Las misiones itinerantes estuvieron constituidas por uno o dos sacerdotes y algunos ayudantes. En localidades que presentaban una densidad poblacional elevada los misioneros resultaban escasos, hecho que dificultaba el adoctrinamiento y que en General Roca incorporaba además el inconveniente de que sus habitantes rechazaban la instrucción religiosa. Esta población generó reacciones ambiguas en los salesianos, ya que por un lado la presencia de aborígenes constituía un fuerte atractivo para cumplir los objetivos de la congregación, pero por otro el comportamiento «inmoral» $\mathrm{y}$ «profano» del huinca los alejaba, porque sus influencias sobre los indígenas provocaban el desvanecimiento de las enseñanzas que les transmitían y complicaba ampliamente su labor (Paesa 1964a).

Desde su participación en la expedición de 1879 los misioneros mostraron un fuerte desprecio por la conducta de los soldados y por el trato profesado a los naturales. En plena campaña, Santiago Costamagna, integrante de la misma, manifestó a su superior: «No se extrañará [...] si alguna vez armado con la caridad de Cristo grite contra esta barbarie civil» (Paesa 1964a: 17). Poco después se lamentaba «¿cómo haremos nosotros, pobres misioneros, para persuadir a esta pobre gente que nuestro Dios es el verdadero mientras ven y oyen todos los días a algunos cristianos que de este Dios no hablan sino para despreciarlos, y que se avergüenzan de ejecutar el menor de los actos de religión?» (Nicoletti 2006: 8). Al radicarse en Carmen de Patagones e iniciar sus desplazamientos por distintos asentamientos y campamentos de Patagonia, los salesianos percibieron que los sitios donde convivían blancos - principalmente soldados-, e indígenas eran los que más obstáculos ofrecían al desempeño de sus funciones. General Roca constituye un ejemplo, ya que era la plaza militar más importante de la línea de frontera sur, asiento de la segunda brigada del ejército; estaba compuesta por tropas numerosas y los salesianos referían continuamente a su rector lo inconveniente de su presencia, dado que sus «malos hábitos» y costumbres «pecaminosas» se difundían y obraban negativamente en el resto de la población (Paesa 1964a). Opinaban que los militares debían ser un ejemplo de orden y honorabilidad, pero en lugar de ello corrompían la moral y el espíritu de todo ambiente humano: «No es fácil alcanzar la conversión de los indígenas, que están obligados a vivir con cierta soldadesca que no les da buenos ejemplos de moralidad», observaba José Fagnano (Paesa 1964a). Para contrarrestar esta situación procuraron tomar el control del agente perturbador e involucrar a los efectivos del ejército en las prácticas religiosas, pero el intento fue inútil.

La población civil blanca también fue señalada como factor perturbador de la obra salesiana y juzgada a veces como «más salvaje que los salvajes mismos»; los comerciantes, que abundaban en General Roca, fueron calificados por Fagnano como «la

\footnotetext{
${ }^{9}$ Cuando el pueblo fue arrasado en 1899 y casi toda su población se trasladó al nuevo ejido urbano dispuesto por el ejército, Stefenelli decidió recomponer la misión en el sitio devastado.
} 
verdadera cruz del misionero», porque fomentaban el consumo de vicios, en especial del alcohol (Fulvi 1981; Paesa 1964a: 22).

De esta manera, civiles y soldados contribuyeron a que los salesianos distinguieran a algunos huincas como «paganos», «inmorales», «indolentes», «inciviles», «indiferentes», «salvajes», de costumbres «bárbaras» e incapaces de transmitir la «verdadera civilización» (Paesa 1964a). La dicotomía civilización-barbarie, abrazada por la congregación en un principio, perdió sentido en Patagonia septentrional. Las condiciones observadas en General Roca y la banalidad de los esfuerzos salesianos en cada misión ambulante provocaron muchas veces su retirada anticipada del lugar: «Se administraron algunos bautismos y se sembró la buena semilla [...] pero al ver tan reducidas esperanzas de frutos, permanecimos pocos días», declaraba Juan Cagliero tras una visita (Paesa 1964a: 40). En la misma nota describía las condiciones de la población y proponía a la sede de Carmen de Patagones organizar misiones de quince días a un mes de duración hasta que se abriera un centro fijo. Intentar regenerar a los civiles se constituyó en otra prioridad misionera para evitar que su conducta inadecuada afectara a los aborígenes. Domingo Milanesio también se pronunció en favor de la instauración de una dependencia para intentar revertir el panorama predominante a través de la continuidad y la constancia de las actividades evangélicas, pero las propuestas no cobraron realidad. En 1886 el sitio aún era descrito como un «campamento moral y espiritualmente revuelto», del cual poco podía obtenerse por la «indiferencia» e «inmoralidad» de sus habitantes (Paesa 1964a: 40). Al año siguiente llegó al paraje la última misión itinerante, integrada por el presbítero Andrés Pestarino y el joven Alejandro Stefenelli, aspirante al sacerdocio.

Durante la década en la que se realizaron misiones ambulantes en General Roca los salesianos enseñaron catecismo, celebraron misas, bautismos, comuniones, confirmaciones, matrimonios, evangelizaron, educaron, procuraron suprimir ciertos prácticas indígenas y protestantes, eliminar «vicios», infundir la predisposición al trabajo, incorporar a los aborígenes a la vida «civilizada» y reinsertar en ella a los blancos «corrompidos» (Paesa 1964a).

\section{Centro misional de General Roca: 1889-1899}

«La luz del evangelio había ya venido clareando ese cielo. Pero aun debía aparecer el sacerdote pionero que se atreviera a romper lanzas con esas arraigadas formas inciviles», manifestaba Paesa (1964a: 44) en relación con las misiones móviles y a la necesidad de establecer una filial salesiana en General Roca. El sacerdote que cumpliría este objetivo sería Alejandro Stefenelli, quién días después de su ordenación (12 de mayo de 1889) recibió la propuesta de Juan Cagliero de radicarse en el asentamiento: «tú sabes que hace mucho tiempo deseo que Roca tenga un sacerdote ... pero ... tú sabes también lo que es aquello y yo en mi conciencia no me siento de mandárselo a nadie...si te quedas eres un valiente» (Paesa 1964a: 47). Estas palabras conmovieron a Stefenelli, que de inmediato aceptó el desafío y un mes más tarde partió hacia el poblado acompañado del ayudante Alfonso Lo Vezio. Al llegar se encontró con un escenario desalentador: «Cerraban el horizonte los nubarrones de un 
muy oscuro abandono moral: indios mantenidos en la miseria y en la abyección, campamentos entregados a los mismos vicios, comerciantes 'indianizados' $\gg{ }^{10}$ (Paesa 1964a: 44). Al advertir la insuficiencia de dos personas para llevar adelante una obra tan ardua, el sacerdote solicitó a Carmen de Patagones el envío de nuevos asistentes, pero sólo remitieron al presbítero Giovanni Roggerone.

La Sociedad Española les ofreció un pequeño edificio para instalarse de manera provisional, recinto que acondicionaron como residencia, escuela para niños y capilla y que inauguraron el día 20 de julio. La misión fue encomendada al arcángel San Miguel, porque Stefenelli consideraba que General Roca requería de un «Presidium contra las insidias del demonio» y el cristianismo concibe a ese arcángel como el guerrero supremo contra éste (Archivo Histórico Salesiano de Patagonia Norte s/f: 157).

Al finalizar el año 1889 el joven Lo Vezio se retiró definitivamente de la misión. La Comandancia prestó a los sacerdotes dos edificios con el objeto de que pudieran desarrollar mejor sus funciones, disponiéndose uno de ellos como escuela y templo y el otro como residencia.

Para cristianizar a los indígenas Stefenelli resolvió centrarse en los niños y jóvenes, convencido de que éstos comentarían a los adultos las enseñanzas adquiridas e involuntariamente les transmitirían el catolicismo; éste constituía un modo alternativo de llevar el evangelio a los padres, ya que por el mayor apego a sus raíces culturales rehusaban el adoctrinamiento pero no se oponían a la instrucción de sus hijos. Juan Bosco había reparado en la importancia de «atraer a los jóvenes y con la educación de los hijos abrirse camino para hablar de religión con los padres», porque creía que si los misioneros trabajaban primero con los más pequeños, los adultos aceptarían oír su prédica «por el natural instinto que lleva a ser benévolo con quien trata con bondad a sus propios hijos»; también reparaba en la posibilidad de que si esos jovencitos crecían «bien instruidos» en el evangelio podrían difundirlo conscientemente entre los miembros de su tribu y éstos al escuchar de su propia gente «la palabra de Dios» la «aceptarían de buena gana» (Nicoletti 2005: 9).

El Estado proclamó a Stefenelli «protector de menores» y bajo la autoridad que le confería este oficio decidió recoger y trasladar al colegio a todos los niños (indígenas y blancos) que residían en la campaña circundante al pueblo y que carecían de los medios necesarios para concurrir diariamente a clases. Los mantuvo como internos y les brindó asilo, alimento, vestido y educación teórica y práctica, esta última a través de talleres de carpintería y zapatería.

En 1890 obtuvo la concesión de media manzana en el centro del pueblo e hizo construir tres instituciones: 1) una escuela de varones con residencias para internos y educadores que comenzó a funcionar en abril del mismo año, 2) una escuela de mujeres con recámaras para internas y maestras, talleres de costura, lavado, planchado y un oratorio, habilitada en 1891 y dirigida por las hermanas de María Auxiliadora (rama femenina de la congregación), y 3 ) un templo para toda la población que abrió sus puertas en 1894.

Antes de que las hermanas se incorporaran a la misión, Stefenelli confesó a Cagliero que no percibía cambios en la conducta de los habitantes y que guardaba gran expec-

${ }^{10}$ Término empleado por los misioneros para aludir a los blancos calificados como «salvajes». 
tativa en la intervención de las religiosas: «Recomienden mucho que recen por esta misión, pues es mucho peor que las del campo. Aquí únicamente se podrá hacer algo, cuando haya un poco de buen ejemplo, que en gran parte se conseguirá llegando las hermanas» (Paesa 1964a: 57). El trabajo de las religiosas dio sus frutos enseguida, y «el ambiente moral y religioso comenzó a elevarse, superando prontamente todas las asperezas» (Paesa 1964a: 60). Este avance llevó tranquilidad al sacerdote, que decidió ocuparse entonces de los adolescentes y empezó a planificar la creación de una escuela de agricultura. Pretendía desarrollar temas vinculados al aprovechamiento del suelo, al manejo de técnicas y prácticas veterinarias y a la organización de pequeñas industrias para comercializar productos obtenibles de la explotación de recursos locales (Belli 1995). Dado que el agro constituía la industria más extendida en esa zona, creía que su conocimiento los protegería contra la pobreza, porque al egresar de la institución podrían emplearse en las chacras de la región o iniciar emprendimientos propios. La entidad comenzó a funcionar en 1894, dictándose las clases teóricas en la escuela primaria y las prácticas en una chacra adquirida al efecto. Con el tiempo se construyeron recámaras y algunos jovencitos quedaron como internos.

En 1898 el Estado cedió a la misión una manzana de 100 x 100 metros, ubicada a una cuadra de los establecimientos anteriores, en la que se levantó un inmenso edificio que reunió el colegio de niños y el de adolescentes.

Pese a que hasta aquí se destacaron principalmente las actividades salesianas sobre la población joven de General Roca - en quienes ya se mencionó que la entidad centraba su atención- también se ocuparon de los adultos. Para ello crearon diferentes instituciones a través de las cuales buscaron dar contención a todos los habitantes del lugar, aunque los aborígenes siempre captaron su atención por constituir la razón de ser de la congregación en Patagonia. La conflictividad advertida durante las misiones itinerantes y los primeros años de funcionamiento de la delegación poco a poco empezó a desvanecerse y a partir de 1891 los escritos de Stefenelli dejaron de exhibir la desazón que primaba en sus informes iniciales. Del mismo modo que había sucedido entre 1880 y 1889, los comportamientos inadecuados que se advirtieron después de esta última fecha también procedieron fundamentalmente del blanco, pero cada vez fueron más esporádicos. Los salesianos que visitaron la localidad después de establecida la filial resaltaron los logros de la misión, tanto a nivel moral, espiritual e incluso material. Por medio de su labor Stefenelli ganó la confianza de civiles e indígenas, que aprovechó para afianzar los objetivos de la congregación dentro del núcleo urbano y en la campaña adyacente.

En julio de 1899, luego de que el pueblo se convirtiera en el asiento más importante del sur de la República (después de Carmen de Patagones), una extraordinaria crecida del río Negro lo destruyó.

\section{Indígenas y blancos bajo el caleidoscopio salesiano}

El examen de documentos elaborados por miembros de la congregación antes de que tomaran contacto con aborígenes de Patagonia y durante los primeros encuentros, permitió vislumbrar sus opiniones iniciales acerca de ellos. Construyeron esos juicios 
sobre la base de las «visiones» y apreciaciones personales de su rector, a comentarios recibidos de terceros, y lecturas de diversas fuentes, y además estuvieron influenciados por nociones del evolucionismo sociocultural y del positivismo, adquiridas en Europa antes de embarcarse hacia Argentina y reforzadas cuando arribaron al país ya que aquí se encontraron con un panorama ideológico semejante. Entre las concepciones más utilizadas por esos marcos teóricos resaltaban las ideas de «progreso», «evolución», «raza», «ciencia», «civilización» y «razón», y uno de los preceptos fundamentales que enunciaban era la «superioridad de la raza blanca». A partir de estos axiomas el indígena fue calificado como un ser inferior y se lo inscribió dentro de categorías como «bárbaro», «salvaje», «irracional», «indómito», «incivilizable»e «inútil», entre otras (Belenky et al. 1980). Más allá de que los salesianos rechazaron algunos de los principios de esas corrientes de pensamiento, a menudo emplearon los calificativos mencionados para aludir a los indígenas. Otro elemento habitual en sus escritos fue considerar al medio ambiente como un factor condicionante del desarrollo sociocultural aborigen, atribuir su comportamiento «primitivo» y el «estancamiento de su evolución» al espacio «hostil» que habitaban, aprehender sus modos de vida como una simple adaptación al entorno y no contemplar la posibilidad de que fueran capaces de modificarlo en su propio beneficio. Esta clase de ideas, de amplia difusión en la época, se inscribe dentro de lo que se conoce como determinismo ambiental, e incluso Juan Bosco mostró estar influenciado por ellas al establecer que las posibilidades de aprendizaje de los diferentes grupos estaban supeditadas al medio en que residían (Nicoletti y Navarro 2001).

$\mathrm{Al}$ comenzar a recorrer Patagonia e intensificar los acercamientos a las poblaciones establecidas allí, los salesianos forjaron un conocimiento cada vez mayor de huincas y aborígenes, lo que les permitió reformular sus ideas en torno a ambos y determinar que la conducta de muchos de los primeros era más «salvaje», «primitiva», «irracional» e «incivilizada» que la de los segundos; asimismo, los acusaron de ser una «influencia negativa»y de transmitirles «malos hábitos» que luego les imputaban y usaban para discriminarlos, denigrarlos y negarles su condición humana. La experiencia que adquirieron a partir del incremento espacio-temporal de las misiones los hizo comprender que la prédica entre indígenas que residían alejados del blanco, o mantenían contactos ocasionales, resultaba más sencilla y proporcionaba mejores resultados que entre aquellos que se relacionaban asiduamente o compartían un mismo espacio físico (Archivo Histórico Salesiano de da Patagonia Norte s/f). Las circunstancias descritas les obligaron a dejar de lado la idea abrazada en un principio respecto a que su convivencia facilitaría la inserción de los indígenas en la sociedad «civilizada». No obstante, pese a haber rectificado sus opiniones acerca de unos y otros, a emplear a veces los mismos términos para referirse a ambos y a que sustentaron el monogenismo - unicidad del género humano-, no abandonaron el supuesto evolucionista de que los aborígenes eran inferiores y no los concibieron como «iguales» (Nicoletti 2006 y 2007). En tanto, el huinca fue percibido como par sin importar el «salvajismo» que profesara, condición que atribuyeron a su radicación en el mismo ambiente «hostil» de los naturales. El misionero Juan Cagliero expuso a Juan Bosco que no lograba aceptarlos como «iguales» y se mostró perturbado frente a la admisión de esa «inferioridad», porque la consideraba incongruente con su formación religiosa (Pasea 
1964a). En este sentido Nicoletti (2004) expresa: «Don Bosco y sus misioneros creían que la humanidad del indígena debía ser necesariamente educada y evangelizada para lograr el estadio de civilización que los equiparara al resto de sus compatriotas» y los convirtiera en «ciudadanos argentinos plenos». Otro misionero, Domingo Milanesio, sostenía que los aborígenes contaban con los principios naturales del desarrollo humano -sentido de sociabilidad, religión y educación-, pero su «vida ruda y sin cultura» había obstaculizado ese desarrollo, manteniendo su humanidad en estado puro, incluso «algo entorpecida» (Nicoletti 2005: 8). Creía que la educación y evangelización salesiana conseguirían desplegar esos principios $-\gg$ herramienta vital para el progreso hacia la 'civilización'»-, los ayudaría a «perfeccionar» el «orden moral y material»-constituyentes substanciales de la cultura según este misionero- y los transformaría en «buenos cristianos» y «buenos ciudadanos» (Nicoletti 2005: 8-9). Esta perspectiva, compartida también por otros misioneros, resultó sumamente conveniente para la congregación, porque no solo justificó la tutela reduccional sino que mostró la actividad misionera como imprescindible para remover a los indígenas del «estado miserable y degradado» en que se hallaban (Nicoletti 2005).

\section{Discusión}

A lo largo de su vida religiosa Juan Bosco tuvo diferentes «sueños premonitorios», por ello cuando se le manifestaron las «visiones» de 1854 y 1872 interpretó que se trataba de «avisos celestiales» y que las escenas observadas tenían correlato en la realidad (Paesa 1964b: 16-17). La descripción que hizo de esos «sueños» permite formar una idea de cómo concibió inicialmente a los aborígenes patagónicos, ya que si bien en el momento que los experimentó no supo que se trataba de ellos, apenas lo determinó les transfirió cada una de las características percibidas. El rector asumió esos «mensajes divinos» como una empresa asignada a la congregación, «elegida» para «salvar las almas» de los indígenas patagónicos y apartarlos del «primitivismo» en que vivían; los ejecutores directos $\rightarrow$-redentores de los salvajes»-serían sus discípulos, que se habían involucrado plenamente con las «visiones» y concebían su consumación a través de la evangelización, educación y «civilización» de los habitantes del sur argentino (Archivo Histórico Salesiano de da Patagonia Norte s/f; Paesa 1964a). «Las posibilidades de redención estaban para Don Bosco claramente enunciadas: Dios a través de la Congregación Salesiana podía proveer misioneros, que siguiendo el plan presentado, los evangelizaran y educaran para lograr la única posibilidad de salvación», expresan Teobaldo y Nicoletti (2007: 184). Juan Bosco ratifica la «elección» de la entidad a partir de manifestar que en su segunda visión distinguió diferentes congregaciones religiosas y sólo los salesianos fueron aceptados por los aborígenes, a quienes recibieron con respeto, les permitieron predicar y les mostraron sumisión y reverencia. Pero esta «elección divina» involucró tanto a la congregación como a los indígenas patagónicos, principales protagonistas de las representaciones oníricas del rector.

El relato de los «sueños» de Juan Bosco, en especial el del segundo, deja entrever el carácter mesiánico y redentor que adjudicó a la obra salesiana en Patagonia, soste- 
nido posteriormente por sus discípulos y perceptible a través de sus escritos ${ }^{11}$. Si bien existen distintas definiciones de mesianismo, la mayor parte de ellas coincide en que el término implica a un grupo de personas que aguardan la llegada de un Mesías, salvador o agente bienhechor (aunque existe el mesianismo múltiple o impersonal), en quien depositan una confianza desmedida y esperan que los «libere» de las condiciones que los oprimen, guiándolos hacia un nuevo orden (Górski 1994: 117). En este trabajo se recurrió al concepto psicológico de mesianismo, que refiere a la conducta particular manifestada por un individuo que abraza la convicción de desempeñar un rol esencial en cuanto a beneficiar a la humanidad, por ser el encargado de llevar adelante una misión concreta, creyendo tener la capacidad de construir una nueva sociedad, una nueva historia, y presentándose él mismo a los demás como Mesías, comportamiento que puede acompañar a un «delirio profético» caracterizado por sueños en los que concibe una «transformación radical de la realidad» (Lischetti 1972). Esta concepción coincide con la posición asumida por Juan Bosco y sus salesianos, porque fueron ellos mismos quienes se asumieron como «salvadores», en principio de los indígenas y luego también de los blancos «corrompidos». Estaban persuadidos de tener una misión específica que cumplir y actuaron de conformidad con ese propósito, incluso, la «transformación radical de la realidad» a partir de «sueños» también los identificó, ya que su empresa en el sur argentino surgió precisamente de la manifestación de dos «sueños» que promovieron el proyecto evangélico, educador y civilizador de la congregación, a través del cual se buscó modificar substancialmente la realidad de los habitantes de Patagonia. En General Roca, Stefenelli exhibió comportamientos afines a este autorreconocimiento mesiánico, sin embargo, al igual que ocurrió con otros salesianos, las acciones que muchas veces consideró «bienhechoras» fueron en realidad paternalistas y se atribuyó licencias sobre los indígenas que utilizó para tomar decisiones acerca de sus vidas y enajenarlos de su juicio y voluntad (Paesa 1964a). Los misioneros fundamentaban esta clase de conductas en que los aborígenes eran incapaces de dirimir acerca de lo más conveniente para sí porque su «primitivismo» les entorpecía la facultad de discernir, razonamiento con que justificaban la imposición de su propio sistema de creencias y valores.

En diferentes informes salesianos la población aborigen de General Roca fue presentada como demonizada. La demonización, como manifestación de racismo, consiste en establecer una relación de superioridad-inferioridad entre individuos o grupos y discriminar a unos u otros a partir de considerarlos dañinos o poseedores de determinados rasgos físicos que el demonizador emplea para conceder un trato diferenciado al demonizado, restringiéndole o anulándole por este medio sus derechos como ser humano (Bello Reguera 2008). Esta conducta puede encubrir distinto tipo de intereses: religiosos, políticos, económicos, culturales y/o sociales, entre los más frecuentes. Rorty (citado en Bello Reguera 2008) declara «que la demonización es, en realidad, una forma de deshumanización y que, por lo tanto, no es necesariamente la única», distinguiendo también la animalización, feminización e infantilización. En Patagonia septentrional los salesianos recurrieron algunas veces a la primera pero más asidua-

\footnotetext{
${ }^{11}$ En los manuscritos que aluden a la labor de la orden entre los habitantes del sur argentino, los salesianos emplearon vocablos como «salvar», «redimir», «liberar», «rescatar», «regenerar», entre los más frecuentes.
} 
mente a la última; al respecto, Nicoletti (2005: 7) cita un pasaje del misionero Domingo Milanesio que revela cómo «un indio adulto es simplemente un niño grande». Cada uno de los aspectos asignados a la demonización, incluso los intereses mencionados, fueron observados en General Roca. Si bien podría plantearse que la población blanca del sitio y de gran parte de la norpatagonia también fue demonizada, ya que los salesianos la calificaron ocasionalmente como «perjudicial» (para los aborígenes), se la excluye de esta categorización porque no fue percibida como inferior, ni se la discriminó por su condición física, ni se le restringieron o anularon sus derechos, y sus diferencias con el blanco «civilizado» fueron concebidas como circunstanciales. Pero esta exclusión del huinca se restringe a la definición académica de la expresión, ya que los misioneros interpretaron el concepto como la influencia del demonio sobre indígenas y blancos, a quien atribuyeron también los «hábitos salvajes» de unos y otros, y por tanto sí los demonizaron (Nicoletti y Navarro 2001: 29). Esta estigmatización quedó registrada en los manuscritos de los salesianos que visitaron General Roca en el periodo de misiones ambulantes y durante los dos primeros años de existencia de la filial, que distinguieron a sus habitantes -indígenas y huincas-como «poseídos». La determinación de abrir una dependencia para trabajar sobre los pobladores de manera constante surgió precisamente del deseo de erradicar al demonio, acción que reforzaron mediante la consagración de la misión al arcángel San Miguel.

Asociar a los habitantes de General Roca con condiciones malignas -además de constituir un aspecto de la demonización- fue una excusa más para someter espiritualmente a los naturales, ya que la orden justificó su propia intervención y la transmisión (imposición) del evangelio - que presentaron como el medio más eficaz para redimirlos- bajo el argumento de pretender «liberarlos» y regresarles la voluntad que se les había quitado. Presentarlos como enajenados y poseídos (deshumanizados) resultó muy conveniente para ignorar la negativa de los indígenas a ser adoctrinados aunque a veces la respetaron-, so pretexto de que no eran éstos sino el demonio el que rehusaba el cristianismo ${ }^{12}$.

Los aborígenes también fueron concebidos como «otros culturales», porque los misioneros juzgaron su conducta en base a la desviación que mostraban de las normas y valores que regían su propia sociedad, es decir, la sociedad occidental. Debido a que para ésta el criterio de medida de la «humanidad normativa» eran sus propios integrantes, los salesianos se compararon con los indígenas y los percibieron como inferiores, razón por la cual los subordinaron y les negaron la «igualdad». Se posicionaron en el rol de estigmatizadores y distinguieron como «otros culturales» a todos los que no reunían las condiciones necesarias para integrar la categoría «nosotros» de la que ellos formaban parte (Rorty 2000). Pero concebirlos como diferentes también les resultó útil para justificar la evangelización, bajo la excusa de transmitirles por ese medio los elementos indispensables para incorporarlos a su misma sociedad.

Los sucesos reseñados hasta aquí permiten vislumbrar el carácter mesiánico que se atribuyó la congregación en General Roca, asumiéndose los salesianos como los úni-

\footnotetext{
12 En realidad, la opinión aborigen no tuvo cabida porque la obra salesiana fue asumida como inobjetable desde el momento en que se le atribuyó un carácter «divino», es decir, desde antes que los misioneros se embarcaran a Argentina.
} 
cos capaces de «rescatar» a la población local de la opresión «demoníaca» en la que vivía, de modificar su presente y de ofrecerle un nuevo orden, acompañado de un futuro promisorio.

\section{Conclusiones}

Ingresar en Patagonia de la mano del ejército contrastó notablemente con el carácter mesiánico y redentor que los salesianos pretendieron asignar a su obra patagónica. Para justificar esta situación refirieron que, frente a los apremios constantes de Juan Bosco para que marcharan hacia el sur, no pudieron rehusar la invitación de Julio Roca, que por otro lado constituyó la oportunidad más segura de avance que se les presentó. En 1878 se habían embarcado hacia Carmen de Patagones pero un fuerte temporal los obligó a regresar a Buenos Aires poco después de zarpar, y por tierra no habían intentado desplazarse porque el desconocimiento de la geografía y de los habitantes del territorio les causaba cierto temor. Frente a este panorama, al recibir la propuesta de Roca «ya estaban dispuestos a entrar [en Patagonia] a cualquier costo», declara el salesiano Antonio Fasulo, porque habían transcurrido casi cuatro años de su llegada a Argentina y aún no lograban empezar a cumplir su encomienda (Nicoletti 2006: 7). Pese a la resolución de marchar con las tropas hicieron saber a su superior la incomodidad que les causaba esa compañía, porque habían observado la indigencia en la que caían los indígenas subyugados y las humillaciones a las que los sometían los soldados. Nicoletti (2006: 10) observa: «Los Salesianos que ingresaron a Patagonia con el ejército y de la mano del Arzobispado de Buenos Aires con monseñor Espinosa, eran conscientes que su misión y el plan de Don Bosco se contradecía fuertemente con las circunstancias violentas y los planes del gobierno argentino». En una carta que Santiago Costamagna escribió al rector durante la travesía le expuso: «¿Pero qué tiene que hacer el Ministro de Guerra y los militares con una Misión de paz? Mi querido Don Bosco es necesario adaptarse por amor o por la fuerza! En esta circunstancia es necesario que la cruz vaya tras la espada, y paciencia!» (Nicoletti 2006: 6). En una ocasión en que José Fagnano marchaba por Tierra del Fuego acompañado de un grupo de soldados éstos dieron muerte a un indígena; enterado Juan Bosco de lo sucedido escribió a este salesiano: « ¿Quiero que los misioneros vayan solos, sin ser escoltados por las armas! Si no es así, será infructuosa su predicación. Sería mejor no ir que hacerlo de esta manera» (Nicoletti 2007: 7). Sin embargo, es difícil determinar hasta qué punto esa compañía los disgustó, porque tiempo después de la expedición el salesiano Lino Carvajal (1900) expuso: «era necesario hacerles sentir todo el peso de la civilización», idea que Nicoletti (2006: 10) refuerza al manifestar: «los misioneros estaban convencidos de la necesidad de una campaña militar que pacificara y abriera el territorio a la civilización». Además, el avance de 1879 no fue la única oportunidad en que marcharon con las tropas, dado que durante sus primeros años de residencia en Patagonia también participaron de otras excursiones, alegando que se integraban a ellas para que los militares los condujeran hasta poblaciones apartadas. En la medida que incrementaron su conocimiento respecto del terreno y sus moradores empezaron a excluirse de esos recorridos. 
Muchos indígenas accedieron a ser evangelizados pero no por convicción sino por conveniencia, ya que de esa forma mantenían buenas relaciones con los misioneros, lograban que intercedieran por ellos ante el Estado y puertas adentro conservaban su cultura. Al respecto, Nicoletti (2008: 14) manifiesta: «Ante la violencia con la que los trataba el ejército, muchos de los indígenas no vieron otra escapatoria que refugiarse en quienes los trataban con más indulgencia». Incluso, respecto a los niños, en quienes la institución se concentraba porque (además de ser uno de sus pilares) abrazaba la idea de que la conversión sería más sencilla debido al menor apego que mostraban a sus raíces (producto de su corta edad), el misionero Domingo Milanesio rectificó esa idea: «los niños indígenas sólo podían ser adoctrinados y persuadidos parcialmente en desconfiar y desatender valores paternos» (Nicoletti 2005: 10). Este «proceso intrínseco de resistencia cultural» ayudó a los indígenas a preservar su esencia frente a instituciones que continuamente intentaron extirpársela, tal es el caso del Estado y de la iglesia, que llegaron a unificar esfuerzos para sojuzgarlos (Nicoletti 2005: 10). De estas instituciones procedieron las imposiciones más categóricas padecidas por los indígenas, opresiones que modificaron su sistema de vida y contra las cuales procuraron oponerse material y culturalmente. Las acciones que estos organismos llevaron adelante, especialmente el primero, fueron a menudo criticadas, incluso por sus integrantes. Un ejemplo significativo lo constituye el relato del soldado Ignacio Fotheringham, integrante del ejército ${ }^{13}$ en 1879 y de campañas posteriores hacia el sur y norte del país, que se refirió al atropello estatal declarando: «Someterlos y atraerlos a la civilización, al amparo de las leyes y convertirlos en buenos y útiles ciudadanos, ¡bellísimo! Pero, llevarles la prédica de la cruz y de las leyes, de la virtud, de la labor honesta y del amor patrio, y tras prédica tan santa llevar la espada, el Rémington y el máuser para convertirlos en...gusanos, no ha de calificarse como muy fraternal ni muy civilizado» (Fotheringham 1971). En cuanto al accionar de los salesianos, un pasaje del texto de Tzvetan Todorov (1987), La conquista de América, que refiere a las políticas implementadas por la iglesia en centroamérica durante la colonia, sirve para ejemplificar el desenvolvimiento de la orden en el sur: «La cristianización, al igual que la exportación de cualquier ideología o técnica, es condenable en el momento mismo en que es impuesta[...]imponer la propia voluntad al otro implica que no se le reconoce la misma humanidad que a uno». Respecto al comportamiento específico de los salesianos Nicoletti (2006: 10) expresa: «Se opusieron a la violencia, porque fieles al plan de Don Bosco, su idea era la de sojuzgar a los indígenas por medio de la religión y protagonizar así este proceso civilizador y pacificador». Este fragmento, que comienza destacando la supuesta oposición de los misioneros a la violencia, en realidad la ratifica, porque el sojuzgamiento es presentado como centro de las ideas de la orden, y Todorov (1987) manifiesta que éste constituye en sí mismo un acto de violencia, sea psíquica o física, porque nace de una imposición. Por lo tanto, de nada importa que la congregación pretendiera subyugar a los aborígenes a través de la religión, porque estaba llevando adelante un proceso que de todos modos era violento y por ende también censurable.

\footnotetext{
${ }^{13}$ Organismo que actuó por orden y en representación del Estado.
} 
A partir de la expedición de 1879 se intensificó la violencia fáctica y psíquica ejercida sobre los habitantes del sur argentino. En tanto el Estado utilizó casi invariablemente la primera para mostrar su autoridad, los misioneros recurrieron a la segunda e intentaron imponerse por medio de la palabra. Las actitudes avasallantes de una y otra entidad y la distancia que separó a la pretendida redención salesiana de los procedimientos que emplearon habitualmente, contribuyeron a que los indígenas se aferraran a sus raíces culturales y nunca les adjudicaran el carácter emancipador con que los miembros de la orden identificaron a su empresa en Patagonia.

Agradecimientos. Quisiera agradecer a Daniel González Lens la lectura crítica del artículo, aunque el mismo es de mi entera responsabilidad.

\section{Referencias bibliográficas}

Archivo Histórico Salesiano de Patagonia Norte

s/f Biografia di Don Alessandro Stefenelli. Missionario Salesiano. Bahía Blanca.

Belenky, Silvia, Carlos Calogero, Leticia Prislei y Olga Weyne

1980 «El pensamiento de los conquistadores del desierto. (A propósito del general Lorenzo Vintter)», en Congreso Nacional de Historia sobre la Conquista del Desierto, vol. 4, pp. 269-278. Buenos Aires: Algraf.

BELLI, Jaime

1995 El Padre A. Stefenelli y la agricultura y el riego en el Alto Valle de Río Negro. General Roca: Chilca Hue.

BELLO

1898 Inspección del Pueblo Gral. Roca (Río Negro). Buenos Aires: Oficina General de Tierras y Colonias de la Nación.

Bello Reguera, Gabriel

2008 «De la demonización al racismo (sobre la deshumanización del otro)». Criterio Jurídico 8 (2): 9-24.

BRUNO, Cayetano

1992 La evangelización de Patagonia y de la Tierra del Fuego. Bahía Blanca: Didascalia.

CARVAJAL, Lino del Valle

1900 Le misionni salesiane nelPatagonia e regioni magallaniche. Studio storico-statistio. San Benigno Canavesse: Scuola Tipografica Salesiana.

ESTRADA, María Alejandra

2006 «Evangelización en la frontera: algo más que religión. Fuerte General Roca (18891913)», en Terceras Jornadas sobre Identidad Cultural y Politica Exterior en la Historia Argentina y Americana, pp. 1-14. Buenos Aires: Universidad del Salvador.

2008 «Migraciones, movilidad y multiculturalidad en norpatagonia a fines del siglo XIX: el caso de la primera General Roca (1879-1899)», en Movilidad y Migraciones. Buenos Aires: Instituto Multidisciplinario de Historia y Ciencias Humanas de CO- 


\section{NICET. [En prensa.]}

FOTHERINGHAM, Ignacio

1971 La vida de un soldado o reminiscencias de las fronteras. Buenos Aires: Biblioteca del Suboficial.

FULVI, Nilo

1981 «Río Negro durante la primera presidencia del General D. Julio A. Roca (18801886). Aspectos Económicos», en Estudios y Documentos n 7, pp. 46-65. Río Negro: Centro de Investigaciones Científicas.

FURQUE, Hilarión

1889 «Somera descripción del territorio nacional de Río Negro. Población. Departamento General Roca». Revista de la Sociedad Geográfica Argentina 69/70: 173-195.

Gorla, Carlos

1973 «Los primeros años de General Roca». Trabajos y Comunicaciones 22: 153-191.

GóRSKY, Eugeniusz

1994 Dependencia y originalidad de la filosofía en Latinoamérica y en la Europa del este. México: Universidad Nacional Autónoma de México.

IRURTIA, María Paula

2002 «La visión de los indios respecto de los 'cristianos' y 'huincas' en el norte de Patagonia, siglos XVIII y XIX», en Funcionarios, diplomáticos, guerreros. Miradas hacia el otro en las fronteras de Pampa y Patagonia (Siglos XVIII y XIX), Lidia Nacuzzi, comp., pp. 247-285. Buenos Aires: Sociedad Argentina de Antropología.

LISCHETTI, Mirtha

1972 «Movimientos prepolíticos en el siglo XX: Mesianismos y milenarismos». Transformaciones. Enciclopedia de los Grandes Fenómenos de Nuestro Tiempo 62.

Ministerio de GUERRA y MARINA DE LA NACIÓN

1884 Memoria del Ministerio de Guerra y Marina presentada al Honorable Congreso por el Ministro General Don Benjamín Victorica en 1884. Buenos Aires: La Tribuna Nacional.

1885 Memoria del Estado Mayor General del Ejército. Anexo a la Memoria del Ministerio de Guerra presentada al Honorable Congreso en 1885. Buenos Aires: La Tribuna Nacional.

1886 Memoria del Ministerio de Guerra y Marina presentada al Honorable Congreso en 1885. Buenos Aires: La Tribuna Nacional.

Nicoletti, María Andrea

2004 «La conflictiva incorporación de Patagonia como tierra de misión (1879-1907)». Boletín Americanista 54: 145-167.

2005 «Evangelizar y educar a los indígenas de Patagonia: conceptos claves de Giovanni Bosco y sus misioneros salesianos (mediados del siglo XIX a principios del siglo XX)». Revista Espacios. Historia Política y Educación 4: 92-106.

2006 «Fuego cruzado: la polémica sobre la conquista y el genocidio patagónico en la congregación salesiana», en Segundas Jornadas de Historia de la Patagonia, pp. 1-20. Roca: Universidad Nacional del Comahue.

2007 «Los salesianos y la conquista de Patagonia: desde Don Bosco hasta sus primeros textos escolares e historias oficiales». Revista Tefros 5 (2): 1-24.

2008 Indigenas y misioneros en Patagonia. Buenos Aires: Continente. 
Nicoletti, María Andrea y Pedro NAVARro Floria

2001 «El aporte de los misioneros salesianos al estudio etnográfico de Patagonia». Saber y Tiempo. Revista de Historia de la Ciencia 12 (3): 27-47.

PAEsA, Pascual

1964a Un pionero del Alto Valle del Río Negro. El Padre Alejandro Stefenelli. Buenos Aires: Escuela Salesiana de Artes Graficas del colegio San José.

1964b El patiru Domingo. La cruz en el ocaso mapuche. Rosario: Escuela Salesiana de Artes Gráficas.

RATTO, Silvia

1999 «Relaciones fronterizas en la provincia de Buenos Aires», en Etnohistoria [CD]. Buenos Aires: Noticias de Antropología y Etnología (NAyA).

RoJAS LAGARDE, Jorge

2004 Malones y comercio de ganado con Chile. Siglo XIX. Buenos Aires: El Elefante Blanco.

RORTY, Richard

2000 Verdad y progreso. Escritos filosóficos 3. Barcelona: Paidós.

TEobaldo, Mirta y María Andrea Nicoletti

2007 «Representaciones sobre Patagonia y sus habitantes originarios en los textos escolares. 1886-1940». Quinto Sol 11: 169-194.

Todorov, Tzvetan

1987 La conquista de América. México: Siglo Veintiuno Editores.

YORIO, Orlando

2003 El deber de civilizar a través de la predicación evangélica en la evangelización de Patagonia. Bahía Blanca: Instituto Superior Juan XXIII.

ZeBAllos, Estanislao

1885 Expedición al desierto. Colección Zeballos. 